\title{
Commentary on "Multiple Personality and Channeling"
}

Richard P. Kluft, M.D.

Temple University School of Medicine, Philadelphia, PA

Follow this and additional works at: https://jdc.jefferson.edu/jeffjpsychiatry

Part of the Psychiatry Commons

Let us know how access to this document benefits you

\section{Recommended Citation}

Kluft, M.D., Richard P. (1991) "Commentary on "Multiple Personality and Channeling"," Jefferson Journal of Psychiatry. Vol. 9 : Iss. 2 , Article 13.

DOI: https://doi.org/10.29046/JJP.009.2.011

Available at: https://jdc.jefferson.edu/jeffjpsychiatry/vol9/iss2/13

This Article is brought to you for free and open access by the Jefferson Digital Commons. The Jefferson Digital Commons is a service of Thomas Jefferson University's Center for Teaching and Learning (CTL). The Commons is a showcase for Jefferson books and journals, peer-reviewed scholarly publications, unique historical collections from the University archives, and teaching tools. The Jefferson Digital Commons allows researchers and interested readers anywhere in the world to learn about and keep up to date with Jefferson scholarship. This article has been accepted for inclusion in Jefferson Journal of Psychiatry by an authorized administrator of the Jefferson Digital Commons. For more information, please contact: JeffersonDigitalCommons@jefferson.edu. 


\title{
In Response
}

\section{Commentary on "Multiple Personality and Channeling"}

\author{
Richard P. Kluft, M.D.
}

In her paper, "Multiple Personality and Channeling," Dr. Rogers compares and contrasts the two phenomena, tries to outline some distinctions between them, and expresses concern lest persons who have the ability to channel be pathologized for their capacity "to engage in a creative social activity which is currently very much in vogue" (p. 11) (1). I appreciate her efforts and here will offer some additional observations and reflections from my own work and experience.

American psychiatry's current models and paradigms offer little opportunity to explore the role of particular traits and qualities that may exert a strong influence upon an individual's subjective experience of the world, and upon the manifestations of psychopathology in that individual. Hypnotizability, dissociativity, absorption, and fantasy-proneness are closely-related and partially-overlapping qualities. The individual who has a high degree of these traits enjoys certain advantages and suffers certain liabilities thereby. Two recent studies have confirmed that individuals who have psychic experiences are more dissociation-prone than normal controls (2,3). An intense and all-encompassing engrossment with one's emotional experiences, imagery, fantasies, and imagination can be gratifying and enriching when such experiences are pleasant and/or are freely sought. However, under duress, the same constellation of traits may lead to the individual's becoming overwhelmed, immersed in unwelcome experiences, pathologically dissociated, and out of touch with reality. For example, many of the experiences that a clinician might attempt to induce in the course of therapeutic hypnosis can be terrifying when they occur as part of a mental disorder, and may be mistaken as sure signs of psychosis. This has led many patients suffering multiple personality disorder (MPD) to be misdiagnosed as schizophrenic (4). The patient with strong traits of a type not assessed in a standard mental status examination is at high risk of being misunderstood and mistreated in a mental health setting.

When two phenomena are to be contrasted, it is useful to observe them both when they occur in isolation and when they cooccur. I have had the opportunity to study channels, MPD patients, MPD patients who channel, and MPD patients who have related capacities (e.g., mediums and fortune-tellers with MPD [5]). I have also 
witnessed and participated in efforts to induce iatrogenic phenocopies of these phenomena.

In the main, channeling or mediumship is a voluntary, sought, and ego-syntonic phenomenon, usually of adult onset. These activities are valued within certain social settings and are without morbidity. Channels and mediums do not interrupt or assume basic life tasks and social roles. They remain restricted to specific ambiances. MPD is an involuntary defense against overwhelming childhood ego-dystonic experiences, and is of childhood onset. Although some patients get significant secondary gain, the usual rewards for MPD are stigmatization, disrupted relationships, and chronic or intermittent dysfunction. The personalities may intrude into all and any areas of function, either assuming them or disrupting them.

Most channels can switch or create circumstances in which they can provoke a switch. Most MPD patients have some degree of voluntary control of the switch process in some alters, but a high degree of such control across all alters is almost always the product of therapy.

Amnesia in MPD usually includes the loss of painful childhood recollections and time loss in the here and now for periods of time in which certain other alters were in control. When channels or mediums have amnesia, it is for the time of such specific activities. They do not experience amnesia for other events. The amnesia in MPD patients deprives them of important information that would help them function more self-protectively. As a result they are prone to revictimization (6). This has not been reported in channelers and mediums.

It is important to realize that MPD is usually covert and indirect in its manifestations, which are the epiphenomena of its defensive purposes. In normal circumstances apart from the therapy setting, only $6 \%$, a small minority of MPD patients, openly call attention to their condition (7). What is most typical of naturalistic MPD is its hiddenness; bland is best. Conversely, the channeling phenomenon is preeminently a social event, the success of which depends on its overtness. Dramatic difference is desirable. Ironically these observations, which are derived from years of clinical observation, are essentially identical to remarks made by a Gypsy woman, who was both a medium and an MPD patient, when I asked her to share her perceptions of her control (the entity that spoke through her when she functioned as a medium) and her alters. She participated in therapy that integrated her alters, but did not treat the control.

I hope that some of these observations extend Dr. Rogers' efforts to distinguish between channeling and MPD.

\section{REFERENCES}

1. Rogers RL: Multiple personality and Channeling. The Jefferson Journal of Psychiatry 9:3-13, 1991

2. Heber AS, Fleischer WP, Ross CA, Stanwick RS: Dissociation in Alternative Healers and Traditional Therapists: A Comparative Study. American Journal of Psychotherapy 43:562_ 574,1989 
3. Richards DG: A Study of the Correlations Between Subjective Psychic Experiences and Dissociative Experiences. Dissociation 4:83-91, 1991

4. Kluft RP: First-Rank Symptoms as a Diagnostic Clue to Multiple Personality Disorder. American Journal of Psychiatry 144:293-298, 1987

5. Kluft RP: Clinical Presentations of Multiple Personality Disorder, Psychiatric Clinics of North America 14:605-629, 1991

6. Kluft RP: Dissociation and Subsequent Vulnerability: A Preliminary Study. Dissociation 3:167-173, 1990

7. Kluft RP: The Natural History of Multiple Personality Disorder. Kluft RP (Ed.): Childhood Antecedents of Multiple Personality. American Psychiatric Press, Washington, DC (pp. 198-238) 